\title{
Cytochrome P450 1A1 and 1B1 promoter CpG island methylation regulates rat liver injury induced by isoniazid
}

\author{
YANHUI LI, YUHONG LI, GUOYING ZHENG, LINGYAN ZHU, \\ JISHUN WANG, SHASHA MU, QI REN and FUMIN FENG
}

\author{
Hebei Province Key Laboratory of Occupational Health and Safety for Coal Industry, School of Public \\ Health, North China University of Science and Technology, Tangshan, Hebei 063200, P.R. China
}

Received August 19, 2016; Accepted July 21, 2017

DOI: $10.3892 / \mathrm{mmr} .2017 .7929$

\begin{abstract}
DNA methylation is an important component of epigenetics that is involved in the occurrence and development of a variety of diseases. The present study aimed to clarify the relationship between cytochrome P450 (CYP)1A1 and CYP1B1 promoter $\mathrm{CpG}$ island methylation and isoniazid-induced liver injury in rats, and to explore the possible mechanism, rats were given an intragastric dose of isoniazid $\left(55 \mathrm{mg} \cdot \mathrm{kg}^{-1} \cdot \mathrm{d}^{-1}\right)$. High performance liquid chromatography was used to analyze the DNA methylation level of the whole genome in liver tissue. Methylation-specific polymerase chain reaction $(\mathrm{PCR})$ was used to detect the methylation level of $\mathrm{CpG}$ islands in the promoter region of CYP1A1 and CYP1B1. Reverse transcription-quantitative PCR was used to determine the mRNA expression levels of CYP1A1, CYP1B1, toll-like receptor 4 (TLR4), extracellular signal-regulated kinase (ERK) 2, peroxisome proliferator-activated receptor (PPAR) $-\gamma$, interleukin (IL)- 6 and tumor necrosis factor (TNF)- $\alpha$. The expression levels of CYP1A1 and CYP1B1 proteins were measured by ELISA, and malondialdehyde (MDA) content and superoxide dismutase (SOD) activity were analyzed by colorimetric method. Liver tissue pathology, an indicator of liver function, indicated rat liver injury at 10 days following isoniazid treatment. Whole-genome methylation levels were gradually reduced, and methylation at day 7 post-treatment was significantly lower than the control group. CYP1A1 and CYP1B1 promoter $\mathrm{CpG}$ island methylation level was significantly increased at 3 days post-treatment. CYP1A1 and CYP1B1 mRNA expression levels were significantly reduced from day 7 and 10, respectively. These results suggested that
\end{abstract}

Correspondence to: Professor Fumin Feng, Hebei Province Key Laboratory of Occupational Health and Safety for Coal Industry, School of Public Health, North China University of Science and Technology, 21 Bohai Road, Tangshan, Hebei 063200, P.R. China E-mail:fm_feng@sina.com

Key words: cytochrome P450 1A1, cytochrome P450 1B1, methylation, isoniazid, liver injury
CpG island hypermethylation of the CYP1A1 and CYP1B1 promoters regulate the low expression of genes involved in the occurrence of isoniazid-induced liver injury. With the alterations of CYP1A1 and CYP1B1 expression, the mRNA expression levels of TLR4, ERK, MDA, IL- 6 and TNF- $\alpha$ were upregulated, and the expression of SOD and PPAR- $\gamma$ were downregulated. These data demonstrated that alterations in methylation patterns may involve changes in the TLR4-ERK signaling pathway and PPAR- $\gamma$, which may alter the expression of MDA, SOD, IL-6 and TNF- $\alpha$, leading to liver injury.

\section{Introduction}

Liver injury is a common side effect of antituberculosis drug treatment, and often leads to the cessation of tuberculosis treatment and the failure of chemotherapy, it is an important clinical problem, but its pathogenesis has not been fully elucidated $(1,2)$. Isoniazid is the preferred drug for the treatment of tuberculosis; it is mainly metabolized through the cytochrome P450 (CYP450) enzyme system, and its main side effect is liver injury (1), which often leads to discontinuation of medication during the treatment of tuberculosis.

CYP450 is the main metabolic enzyme that is involved in phase I reactions and in the metabolism of endogenous and exogenous compounds (3). Other studies have reported on correlations between the subtypes of P450 and diseases (45), and previous molecular epidemiological studies indicated that the genetic polymorphism of CYP450 metabolic enzymes may be related to the occurrence of anti-tuberculosis drug-induced liver injury (ADLI) (6). It was also suggested that ADLI may be related to the decrease of drug metabolism enzyme activity and the accumulation of metabolites. Alteration or loss of the activity of the metabolic enzyme may result in an imbalance of cellular detoxification functions, resulting in liver disease (7).

In epigenetics, promoter methylation is an important mechanism for the downregulation or inactivation of gene expression, except gene mutation and deletion (8), and a study on mammalian found that $\mathrm{CpG}$ dinucleotide methylation is associated with the inhibition of gene expression. CpG islands in the promoter region are rich in $\mathrm{CpG}$ sites, and under normal circumstances are non-methylated, whereas $\mathrm{CpG}$ sites outside of the $\mathrm{CpG}$ islands are usually methylated. Abnormal changes have taken place in the methylation patterns in cancers or 
other diseases (9). High levels of methylation in $\mathrm{CpG}$ islands were reported to result in the downregulation of gene expression, which may be an underpinning cause of disease (10-12). Downregulation of genome-wide methylation levels may be observed in hepatic inflammatory disease, hysteric apepsia, immune deficiency and tumors. Genome-wide hypomethylation may result in chromosome conformation opening up and transcriptional activation, which may lead to chromosome instability and abnormal gene expression. Alterations in whole-genome DNA methylation level have been considered as a biomarker of tumor development (13). In a case-control study, $\mathrm{CpG}$ island methylation in the CYP1A1 promoter region served an important role in ADLI (14). Animal experiments also confirmed that CYP2E1 promoter hypermethylation and genome-wide hypomethylation was associated with liver injury induced by isoniazid $(15,16)$. These results suggested that CYP1A1 and CYP1B1 promoter $\mathrm{CpG}$ island methylation and isoniazid-induced rat liver injury may be related.

Alterations in toll-like receptor (TLR)-4 mRNA expression and its signaling pathway were observed in liver injuries induced by acetaminophen, floxacillin, methimazole, lipopolysaccharide and alcohol (17). TLR4 has been reported to serve an important role in drug-induced liver injury, and TLR4 signal transduction cascades may be related to the cause of these diseases (18). A previous study on alcoholic fatty liver ischemia-reperfusion injury demonstrated that the enzyme activity and gene expression of CYP1A1, CYP1A2 and CYP2B1 were decreased following ischemia-reperfusion, but the activity and expression of CYP2E1 were increased (19). The results from this previous study revealed the overexpression of CYP2E1 in Kupffer cells, which induce TLR4 activation, produced inflammatory responses and may lead to liver damage (19). Under exposure to aflatoxin B1 (AFB1), the observed pronounced increase in TLR4 transcripts in monocytes may be partly attributed to higher expression of CYP1A1 and CYP1B1 caused by AFB1 peroxidation in monocytes (20). Extracellular signal-regulated kinase (ERK) is downstream of TLR4, and may also be involved in the regulation of DNA methylation patterns by regulating methyltransferase. Peroxisome proliferator-activated receptors (PPARs) are a type of nuclear receptor that may be activated by the peroxisome proliferator, and that regulate the inflammatory response, lipid metabolism, cell proliferation and differentiation in the liver. The regulation of PPAR- $\gamma$ in liver diseases may serve an important role. Cyclophosphamide may cause severe liver damage through CYP metabolism transformation; PPAR- $\gamma$ was revealed to be significantly reduced in the liver injury induced by cyclophosphamide (21). After receiving liver-protective treatment, activated PPAR- $\gamma$ downregulated signal transducer and activator of transcription, nuclear factor- $\mathrm{\kappa B}$ and activator protein-1 signaling pathways, oxidative stress and the inflammatory response were reduced, and liver injury was lessened (21).

DNA methylation may be modified by promoter demethylation, which may increase the expression of the silenced gene and thus restore the expression. This provides a basis for the prevention and treatment of disease. Currently, there are few studies on the relationship between drug metabolism-enzyme methylation and ADLI; therefore the present study aimed to analyze the relationship between two important drug metabolizing enzymes CYP1A1 and CYP1B1 promoter methylation and isoniazid-induced liver injury in rats and the possible mechanism, to provide insight for the prevention and treatment of liver injury, and to enhance the effectiveness of the treatment of tuberculosis.

\section{Materials and methods}

Animals and treatments. A total of 56 specific-pathogen free Sprague-Dawley rats (28 male, 28 female; age, 8-9 weeks) were purchased from Beijing Hua Fukang Biotechnology Co., Ltd. (Beijing, China). The present study was approved by the Ethics Committee of North China University of Science and Technology (Tangshen, China). All rats were maintained at $22-23^{\circ} \mathrm{C}$ with $65-69 \%$ humidity, a $12 / 12 \mathrm{~h} \mathrm{light/dark}$ cycle and with free access to food and water. Following 1 week of adaptive feeding, the rats were randomly divided into 7 groups ( 8 rats/group); the control group, which received an equal volume of distilled water and were sacrificed at day 28 , and the remaining 48 rats were subsequently divided into 6 groups (labeled as day 3, 7, 10,14, 21 and 28, respectively), which were gavaged with isoniazid $\left(55 \mathrm{mg} \cdot \mathrm{kg}^{-1} \cdot \mathrm{d}^{-1}\right.$; Shenyang Hongqi Pharmaceutical Co. Ltd, Shenyang, China) and were subsequently sacrificed at day 3, 7, 10, 14, 21 and 28. Following sacrifice, blood and liver tissues were collected. Blood was collected using K2-EDTA as an anticoagulant; serum was separated by centrifugation at $4,000 \mathrm{xg}$ for $10 \mathrm{~min}$ at $4^{\circ} \mathrm{C}$. Serum samples and liver tissues were stored at $-80^{\circ} \mathrm{C}$.

Histopathological investigation. Liver specimens were fixed in $10 \%$ buffered formalin solution, embedded in paraffin and sections $(4 \mu \mathrm{m})$ were stained with hematoxylin and eosin. Images were captured with an Eclipse 80i optical microscope (Nikon Corporation, Tokyo, Japan). Pathological changes were observed under x20 magnification.

Serum alanine aminotransferase (ALT) and aspartate aminotransferase (AST) levels. $3 \mathrm{ml}$ serum was collected following sacrifice, and the levels of ALT and AST were measured with a Hitachi Biochemical Analyzer (Hitachi, Ltd., Tokyo, Japan).

DNA and RNA extraction. DNA and RNA were extracted from $20 \mathrm{mg}$ liver tissue of experimental rats using a Tissue Genomic DNA Extraction kit and an EASYspin Plus RNA kit (Aidlab Biotechnologies Co., Ltd, Beijing, China), respectively, according to the manufacturer's protocol. Absorbance values were measured using an ultraviolet spectrophotometer to determine the concentration and quality of extracted nucleic acids, 260/280 nm between 1.8 and 2.0 indicated that the extracted nucleic acid was superior in quality.

Detection of genome-wide methylation level. Perchloric acid $(70 \% ; 25 \mu \mathrm{l})$ was added to DNA $(50 \mu \mathrm{l})$ and incubated in a $95^{\circ} \mathrm{C}$ water bath for $50 \mathrm{~min} . \mathrm{KOH}(1 \mathrm{~mol} / \mathrm{l})$ was used to adjust the $\mathrm{pH}$ to between 3 and 5, and the samples were centrifuged at $18,500 \mathrm{xg}$ for $10 \mathrm{~min}$ at $4^{\circ} \mathrm{C}$, and the supernatant was aliquoted to a clean tube. Methylation levels were determined using an Agilent 1200 High Performance Liquid Chromatography (HPLC) System (Agilent Technologies, Inc., Santa Clara, CA, USA). Separation was achieved with a $150 \times 4.6 \mathrm{~mm}, 5 \mu \mathrm{m}$ Agilent Eclipse XDB-C18 
Table I. Expected product size and primer sequences used for methylation polymerase chain reaction.

\begin{tabular}{|c|c|c|}
\hline Gene & Primer sequence $\left(5^{\prime} \rightarrow 3^{\prime}\right)$ & Product size (bp) \\
\hline \multirow[t]{4}{*}{ CYP1A1 } & MF:GGTTTTTGTTTTTAGGTAGAAGTCG & 202 \\
\hline & MR:GCGAATCCCAATACTATCACG & \\
\hline & UF:TGTTAGGTTTTTGTTTTTAGGTAGAAGTT & 208 \\
\hline & UR:CACAAATCCCAATACTATCACACT & \\
\hline \multirow[t]{4}{*}{ CYP1B1 } & MF: GCGGCGATTAAGTATTTTTC & 159 \\
\hline & MR:ATCTCCCTAAACGCTACTCG & \\
\hline & UF:TTGGTGGTGATTAAGTATTTTTT & 159 \\
\hline & UR:ATCTCCCTAAACACTACTCACAA & \\
\hline
\end{tabular}

CYP, cytochrome P450; F, forward; M, methylated; R, reverse; U, unmethylated.

column (Agilent Technologies, Inc.) using methanol:water (1:9 $\mathrm{v}: \mathrm{v})$ as the mobile phase and a flow rate of $0.3 \mathrm{ml} / \mathrm{min}$. The injection volume was $20 \mu \mathrm{l}$, column temperature was $25^{\circ} \mathrm{C}$ and the detection wavelength was $284 \mathrm{~nm}$. Pure products of $5 \mathrm{C}$ and $5 \mathrm{mC}$ were used as standards to prepare concentration gradients. External calibration of peak area vs. concentration was used in the determination of global DNA methylation levels: $5 \mathrm{mC}(\%)=[5 \mathrm{mC} /(5 \mathrm{mC}+5 \mathrm{C})] \times 100 \%$; where $5 \mathrm{mC}$ is 5 -methylcytosine.

Determination of $\mathrm{Cp} G$ island methylation level in CYP1A1 and CYPIB1 promoter regions by polymerase chain reaction (PCR). $5 \mu \mathrm{l}(200 \mathrm{ng} / \mu \mathrm{l})$ DNA was modified by EZ DNA Methylation-Gold Kit (Zymo Research Corp., Irvine, CA, USA) according to the manufacturer's protocol. Methylated and unmethylated primers for CYP1A1 and CYP1B1 were synthesized by Shanghai Shengong Biological Engineering Technology Service, Ltd. (Shanghai, China) (Table I). Methylation specific PCR (MSP; Applied Biosystems; Thermo Fisher Scientific, Inc., Waltham, MA, USA) using the following cycle parameters: $95^{\circ} \mathrm{C}$ for $5 \mathrm{~min}$, followed by 40 cycles at $95^{\circ} \mathrm{C}$ for $30 \mathrm{sec}, 55^{\circ} \mathrm{C}$ for $30 \mathrm{sec}$ and $72^{\circ} \mathrm{C}$ for $30 \mathrm{sec}$, and a final extension at $72^{\circ} \mathrm{C}$ for $7 \mathrm{~min}$. PCR products $(2 \mu \mathrm{l})$ were subjected to electrophoresis on $2 \%$ agarose gels and stained with $0.5 \mu \mathrm{g} / \mathrm{ml}$ ethidium bromide. Optical density values were measured using Quantity One 4.6.2 (Bio-Rad Laboratories, Inc., Hercules, CA, USA). The following formula was used to calculate the results of methylation: Methylation rate $(\%)=[\mathrm{O}$ $\left.\mathrm{D}_{\mathrm{M}} /\left(\mathrm{OD}_{\mathrm{M}}+\mathrm{OD}_{\mathrm{U}}\right)\right] \mathrm{x} 100 \%$; where $\mathrm{U}$ indicates unmethylated and $\mathrm{M}$ indicates methylated.

Reverse transcription-quantitative PCR (RT-qPCR). Total RNA (50 ng) from liver tissue was reverse transcribed using an M-MLV kit (Invitrogen; Thermo Fisher Scientific, Inc.) according to the manufacturer's protocol. cDNA synthesis was conducted at $37^{\circ} \mathrm{C}$ for $15 \mathrm{sec}$ followed by $85^{\circ} \mathrm{C}$ for $5 \mathrm{~min}$. cDNA products were amplified using the primers presented in Table II; GAPDH was used for normalization of the quantity of cDNA. qPCR was performed with an ABI StepOne Real-Time PCR System (Applied Biosystems; Thermo Fisher Scientific, Inc.) was carried out in a $20 \mu 1$ reaction mixture using the Platinum SYBR Green qPCR kit (Invitrogen; Thermo Fisher Scientific, Inc.) containing $2 \mu \mathrm{l}$ cDNA sample, $10 \mu \mathrm{l} 2 \mathrm{X}$ SYBR
Green, $0.4 \mu \mathrm{l}$ ROX and $1.6 \mu \mathrm{l}$ of the primers (0.8 $\mu \mathrm{l}$ upstream primers and $0.8 \mu 1$ downstream primers), with $6 \mu 1$ of DEPC water. The thermocycling program was: $95^{\circ} \mathrm{C}$ for $10 \mathrm{~min}$, followed by 40 cycles of $95^{\circ} \mathrm{C}$ for $15 \mathrm{sec}, 63^{\circ} \mathrm{C}$ for $30 \mathrm{sec}$ and $72^{\circ} \mathrm{C}$ for $30 \mathrm{sec}$ (the annealing temperature of each gene is shown in Table II). Relative expression was calculated using the $2^{-\Delta \Delta \mathrm{Cq}}$ method (22).

ELISA. Liver tissue (10 g) was used to prepare a $10 \%(\mathrm{w} / \mathrm{v})$ tissue homogenate with phosphate-buffered-saline (PBS) (0.02 M sodium phosphate buffer with $0.15 \mathrm{M}$ sodium chloride, $\mathrm{pH}$ 7.4). The homogenate was centrifuged at 4,500 x g for $10 \mathrm{~min}$ at $0^{\circ} \mathrm{C}$. Protein expression levels of CYP1A1 and CYP1B1 were determined using rat ELISA kits (P4501A1 and P4501B1, respectively) (both from Beijing Winter Song Boye Biotechnology Co., Ltd, Beijing, China), according to the manufacturer's protocols. Absorbance was measured at $450 \mathrm{~nm}$ with a microplate reader.

Superoxide dismutase (SOD) and malondialdehyde (MDA) levels. SOD activity and MDA content was detected using a Malondialdehyde assay kit and a Superoxide Dismutase assay kit (Jiancheng Bioengineering Ltd, Nanjing, China) according to the manufacturer's instructions. Homogenates were prepared as aforementioned and diluted prior to use as follows: SOD activity, $10 \%$ homogenate (w/v); MDA content, $0.25 \%$ homogenate (w/v). Absorbance was measured at 550 and $532 \mathrm{~nm}$ with a microplate reader, respectively.

Statistical analysis. Data are presented as the mean \pm standard deviation. Difference among groups was tested by one-way analysis of variance with Fisher's least significant difference or Dunnett's T3 (equal variances not assumed following the variable transformation justification) post hoc test using SPSS 17.0 software (SPSS, Inc., Chicago, IL, USA). Correlation analysis using Pearson's correlation analysis reflected the true correlation of two variables using partial correlation analysis. $\mathrm{P}<0.05$ was considered to indicate a statistically significant difference.

\section{Results}

Validation of rat liver injury model. Tissue pathology is the gold standard for the diagnosis of liver injury, and ALT and 
Table II. Primer sequences and annealing temperatures for reverse transcription-quantitative polymerase chain reaction.

\begin{tabular}{|c|c|c|}
\hline Gene & Primer sequence $\left(5^{\prime} \rightarrow 3^{\prime}\right)$ & Annealing temperature $\left({ }^{\circ} \mathrm{C}\right)$ \\
\hline \multirow[t]{2}{*}{ GAPDH } & F:AGCAACTCCCATTCTTCC & 63 \\
\hline & R:GTCCAGGGTTTCTTACTCC & \\
\hline \multirow[t]{2}{*}{ CYP1A1 } & F:CAGACCCAACACTGGCATC & 63 \\
\hline & R:GGGAGGTAACGGAGGATAGG & \\
\hline \multirow[t]{2}{*}{ CYP1B1 } & F:GAGAGTTGGTGGCAGTGTTG & 63 \\
\hline & R:CCAGGACGAAGTTGCTGAA & \\
\hline \multirow[t]{2}{*}{ TLR4 } & F:GCCTCCCTGGTGTTGGATTT & 57 \\
\hline & R:AGCACACTGACCACCGATAC & \\
\hline \multirow[t]{2}{*}{ ERK } & F:GGCACCAACCATTGAGCAGA & 63 \\
\hline & R:GATCATTGCTGAGGTGCTGTGTC & \\
\hline \multirow[t]{2}{*}{ PPAR- $\gamma$} & F:CGTCCCCGCCTTATTATTCT & 63 \\
\hline & R:GCTTTATCCCCACAGACTCG & \\
\hline \multirow[t]{2}{*}{ IL-6 } & F:ACAGCGATGATGCACTGTCA & 60 \\
\hline & R:AGCACACTAGGTTTGCCGAG & \\
\hline \multirow[t]{2}{*}{ TNF- $\alpha$} & F:CTCAAGCCCTGGTATGAGCC & 60 \\
\hline & R:GGCTGGGTAGAGAACGGATG & \\
\hline
\end{tabular}

CYP, cytochrome P450; F, forward; R, reverse; TLR4, toll-like receptor 4; ERK, extracellular signal-regulated kinase; PPAR- $\gamma$, peroxisome proliferator-activated receptor- $\gamma$; IL-6, interleukin- 6 ; TNF- $\alpha$, tumor necrosis factor- $\alpha$.

AST levels are important indicators of liver function and pathological changes in the laboratory. H\&E stained sections of rat liver tissues were examined under a light microscope to observe the pathological changes (Fig. 1). In the normal control group, the liver cells appeared normal, the structure of the liver was complete, liver cells were in radially arranged cords, with the central vein as the center, arranged neatly and clearly defined (Fig. 1A). In the rats groups treated with isoniazid, a large number of inflammatory cells infiltration and hepatic edema was observed, and the polygonal arrangement became spherical in shape with irregular structure at day 10 (Fig. 1D). At day 14, the cytoplasm was loose and balloon-like degeneration was diffuse, liver cell structure was disordered and partial liver cells were degenerated and necrotic (Fig. 1E). At day 28 , the structure of hepatic leaflets was completely destroyed, and most of the hepatic cells were necrotic, focal necrosis and bridging necrosis were clearly visible (Fig. 1G). Alterations in the levels of ALT and AST, as measured by automatic biochemical analyzer, were also revealed to increase with time of following isoniazid administration (Table III), and the difference was statistically significant from 10 day $(\mathrm{P}<0.05)$. The pathological results and liver function indices indicated that isoniazid treatment successfully induced rat liver injury in the animal models.

Analysis of genome methylation level. Whole-genome methylation status is related to the stability of the genome. HPLC analysis provided a good separation of $5 \mathrm{C}$ and $5 \mathrm{mC}$; the standard curves of $5 \mathrm{C}$ and $5 \mathrm{mC}$ were $\mathrm{Y}=75.194 \mathrm{X}-16.914$ ( $\mathrm{r}=0.999$; Fig. 2A), Y=89.829X-6.7363 (r=0.999; Fig. 2B), respectively. Chromatograms of the control group and a representative experimental group are presented in Fig. 3A and B, respectively. Whole-genome methylation levels at days 7, 10, 14, 21
Table III. Levels of serum alanine aminotransferase and aspartate aminotransferase in each group following administration of isoniazid.

\begin{tabular}{lcc}
\hline Group & ALT $\left(\mathrm{U} / 1^{-1}\right)$ & AST $\left(\mathrm{U} / 1^{-1}\right)$ \\
\hline Control & $20.23 \pm 4.22$ & $80.28 \pm 26.41$ \\
Day 3 & $28.98 \pm 10.96$ & $89.16 \pm 16.92$ \\
Day 7 & $34.85 \pm 22.72$ & $119.95 \pm 52.24$ \\
Day 10 & $83.85 \pm 24.35^{\mathrm{a}}$ & $189.97 \pm 35.80^{\mathrm{a}}$ \\
Day 14 & $114.50 \pm 33.33^{\mathrm{a}}$ & $243.28 \pm 62.16^{\mathrm{a}}$ \\
Day 21 & $118.25 \pm 24.60^{\mathrm{a}}$ & $202.36 \pm 101.91^{\mathrm{a}}$ \\
Day 28 & $96.10 \pm 26.25^{\mathrm{a}}$ & $170.63 \pm 77.52^{\mathrm{a}}$ \\
\hline
\end{tabular}

Values are presented as the mean \pm standard deviation $(n=8) .{ }^{\mathrm{a}} \mathrm{P}<0.05$, vs. control group.

and 28 were significantly decreased compared with the control group, which indicated that the whole-genome methylation level was abnormal.

Analysis of methylation levels of CpG islands in CYP1A1 and $1 B 1$ promoter regions and $m R N A$ and protein expression levels. Gene promoter region-specific hypermethylation and whole-genome hypomethylation occur side-by-side within the same individual in certain disease states. The abnormal methylation pattern of promoter region can lead to the change of gene expression, and then participate in the occurrence of disease (23). Isoniazid may also induce these abnormalities in liver injury. The present study used MSP to measure the methylation level of 

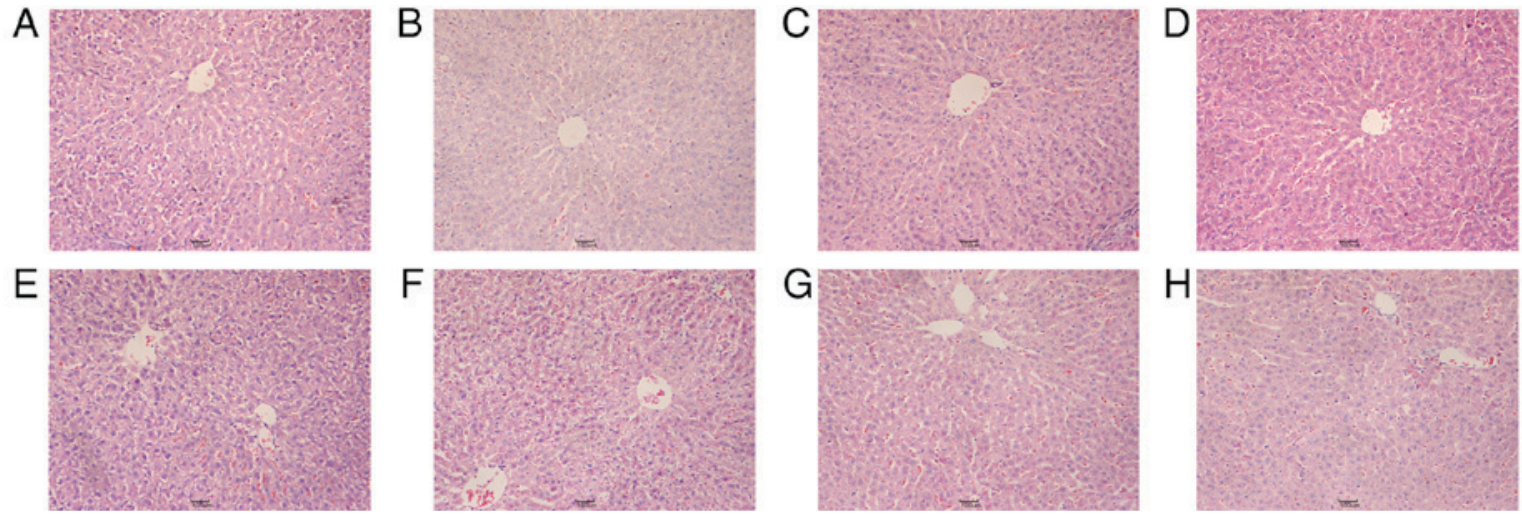

Figure 1. Hematoxylin and eosin staining histopathological results of rat liver tissue following intragastric administration of isoniazid. (A) Normal control group. (B) 3 days post-isoniazid treatment. (C) 7 days post-treatment. (D) 10 days post-treatment. (E) 14 days post-treatment. (F) 21 days post-treatment. (G and $\mathrm{H}) 28$ days post-treatment. Magnification, $\mathrm{x} 20$.

A

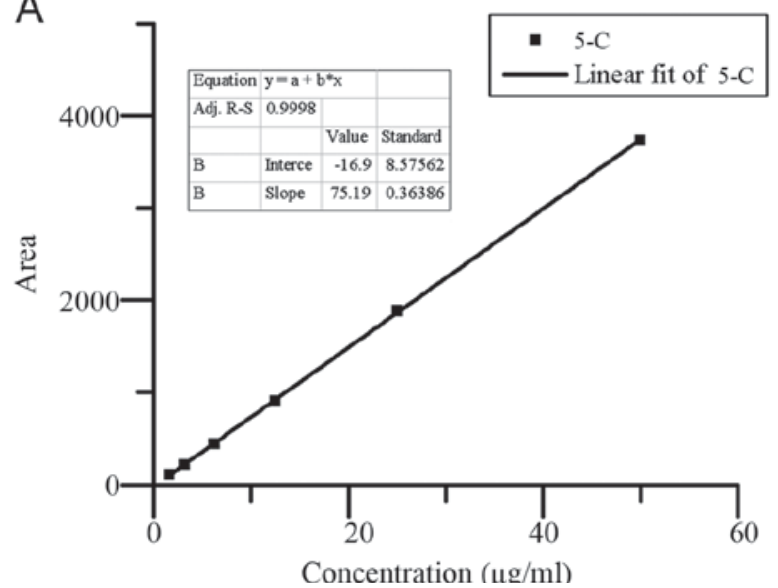

B

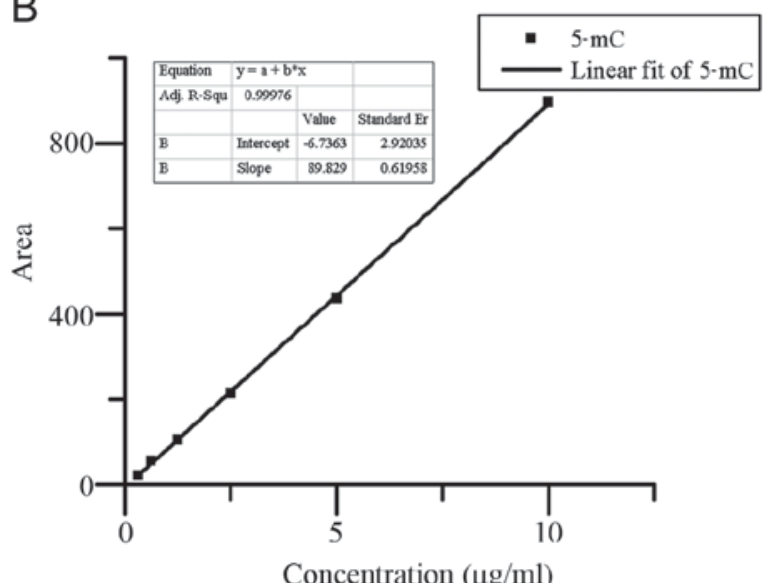

Figure 2. Standard curves for series concentrations of $5 \mathrm{C}$ and $5 \mathrm{mC}$. (A) $5 \mathrm{C}$ as standard; the concentration series was 50, 25, 12.5, 6.25, 3.175 and 1.5875 $\mu \mathrm{g} / \mathrm{ml}$. (B) $5 \mathrm{mC}$ as standard; the concentration series was 10, 5, 2.5, 1.25, 0.625 and $0.3125 \mu \mathrm{g} / \mathrm{ml}$. 5C, 5-cytosine; 5mC, 5-methylcytosine.

A

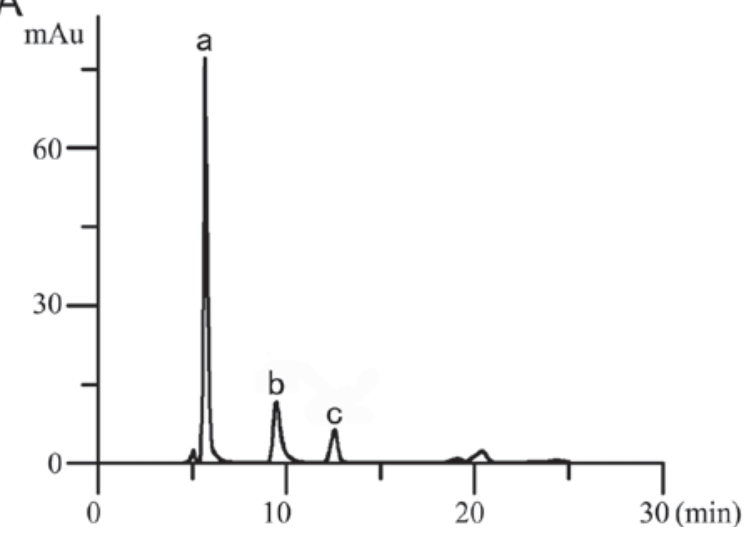

B

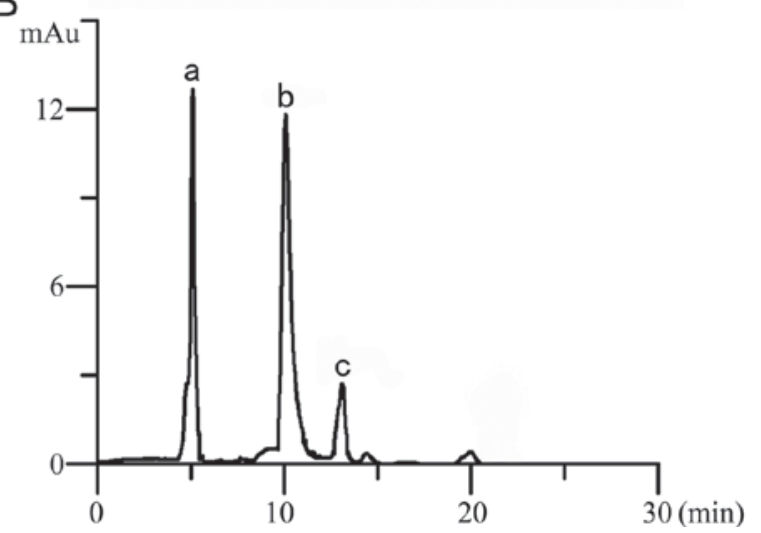

Figure 3. High-performance liquid chromatography chromatograms of control group and experimental group. (A) A sample from the control group. (B) A representative sample from the experimental group. The peaks are labeled as following: Solvent (a); 5C (b); 5mC (c). mAu, milli-absorption units. 5C, 5-cytosine; 5mC, 5-methylcytosine.

$\mathrm{CpG}$ islands in the gene promoter regions. Compared with the control group, $\mathrm{CpG}$ island methylation levels of the CYP1A1 and CYP1B1 promoter regions significantly increased over time from day 3 following isoniazid administration (Fig. 4). Alterations in methylation levels were detected earlier than the changes in liver function and liver tissue pathology, which indicted that methylation of the gene promoter region may be able to regulate the occurrence of liver injury.

CYP1A1 and CYP1B1 mRNA expression levels exhibited a downward trend over time (Fig. 5A). CYP1A1 mRNA 
expression levels were significantly different from day 7 post-isoniazid treatment, whereas CYP1B1 expression was significantly lower from 10 day compared with their respective untreated control group. Protein expression levels of both CYP1A1 and CYP1B1 were significantly decreased from day 10 compared with their respective controls (Fig. 5B).

With increasing time post-treatment, the methylation of CpG islands in the CYP1A1 and CYP1B1 gene promoter regions gradually increased, whereas the gene expression level was gradually decreased. Correlation analysis indicated that the methylation levels of the CYP1A1 promoter region were negatively correlated with its mRNA and protein expression levels $(r=-0.824$ and -0.518 respectively; $\mathrm{P}<0.05)$; similar results were indicated for CYP1B1 mRNA and protein expression levels compared with promoter methylation level $(\mathrm{r}=-0.559$ and -0.420 , respectively; $\mathrm{P}<0.05)$. The correlation between $\mathrm{CpG}$ island methylation level and gene expression level in CYP1A1 was higher than that for CYP1B1, which suggested that the expression of CYP1A1 may be more susceptible to regulation by methylation of $\mathrm{CpG}$ islands in the promoter region.

Correlation analysis also demonstrated that the CYP1A1 mRNA expression levels were negatively correlated with the expression of ALT and AST ( $\mathrm{r}=-0.632$ and -0.403 , respectively; $\mathrm{P}<0.05)$, and similar results were noted for CYP1B1 and ALT and AST expression levels ( $\mathrm{r}=-0.395$ and -0.187 , respectively; $\mathrm{P}>0.05$ ). Compared with CYP1B1, the correlation coefficient of CYP1A1 and ALT and AST was greater and indicated a potentially closer relationship between CYP1A1 and isoniazid-induce liver injury compared with CYP1B1 and liver injury.

Alterations in $m R N A$ expression level of TLR4, ERK, $P P A R-\gamma$. Previous studies have indicated that the changes in TLR4, ERK, PPAR- $\gamma$ signaling were regulated by CYPs, and were related to liver injury (17-21). Therefore, the relative mRNA expression levels of TLR4, ERK and PPAR- $\gamma$ were evaluated by RT-qPCR following isoniazid exposure (Fig. 6). The expression levels of TLR4 and ERK exhibited an upward trend from day 3 and 7, respectively, and these expression levels were significantly increased compared with their respective controls. The expression of PPAR- $\gamma$ exhibited a significant decrease in mRNA expression from day 7 compared with expression in the untreated control rats. These results indicated that the TLR4 signaling pathway and PPAR- $\gamma$ may participate in liver injury induced by isoniazid. However, it is unknown whether the changes in these signaling pathway related factors are related to the expression changes of CYP1A1 and CYP1B1.

Correlation analysis suggested that TLR4 was positively correlated with ALT and AST expression $(r=0.449$ and 0.355 , respectively; $\mathrm{P}<0.05)$, and negatively correlated with the mRNA expression levels of CYP1A1 and CYP1B1 ( $r=-0.627$ and -0.647 , respectively; $\mathrm{P}<0.05$ ). ERK was also positively correlated with ALT and AST ( $\mathrm{r}=0.634$ and 0.499 , respectively; $\mathrm{P}<0.05$ ), and negatively correlated with the mRNA expression level of CYP1A1 and CYP1B1 ( $r=-0.541$ and -0.436 , respectively; $\mathrm{P}<0.05$ ). PPAR $-\gamma$ was negatively correlated with ALT and AST expression ( $r=-0.512$ and -0.409 , respectively; $\mathrm{P}<0.05$ ), and positively correlated with the

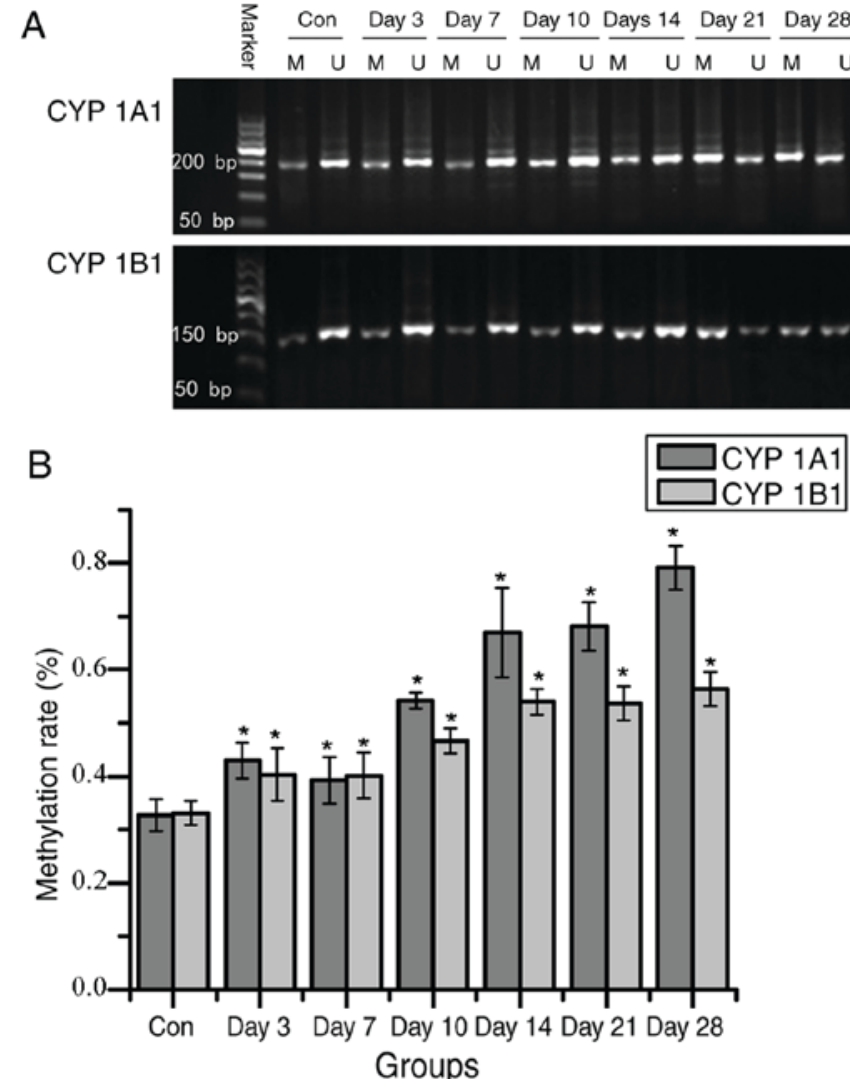

Figure 4. Electrophoretic pattern of MSP products and the methylation level of $\mathrm{CpG}$ islands in the promoter region. (A) MSP products for CYP1A1 and CYP1B1 on a 2\% agarose gel (B) Methylation levels of CYP1A1 and CYP1B1 promoter regions; methylation levels (\%) were calculated as the density of the $\mathrm{M}$ band vs. the total density of $\mathrm{U}+\mathrm{M}$. Each value is presented as the mean \pm standard deviation of three experiments; " $\mathrm{P}<0.05$ vs. respective control. Con, control; CYP, cytochrome P450; M, methylated; MSP, methylation-specific polymerase chain reaction; $\mathrm{U}$, unmethylated.

mRNA expression level of CYP1A1 and CYP1B1 ( $r=0.599$ and 0.387 , respectively; $\mathrm{P}<0.05$ ).

Partial correlation analysis was performed to control the mRNA expression level of CYP1A1 and CYP1B1, and the correlation coefficients of TLR4, ERK and PPAR- $\gamma$ mRNA, and ALT and AST were significantly decreased. The partial correlation coefficients of mRNA expression of TLR4 and ALT and AST were 0.078 and 0.193 , respectively $(P>0.05)$. The partial correlation coefficients of mRNA expression of ERK and ALT and AST were 0.449 and 0.384, respectively $(\mathrm{P}<0.05)$. The partial correlation coefficients of mRNA expression of PPAR- $\gamma$ and ALT and AST were -0.213 and -0.233 , respectively $(\mathrm{P}>0.05)$. These data demonstrated that the correlation is significantly reduced, which indicated that the expression level of TLR4, ERK and PPAR- $\gamma$ in liver injury may be regulated by the expression of CYP1A1 and CYP1B1.

Detection of oxidative stress and immune-related indices. Oxidative stress and inflammation are involved in many kinds of liver injury, and TLR4 signaling and PPAR- $\gamma$ may alter downstream gene expression or signal pathways to affect changes in IL-6, TNF- $\alpha$, MDA and SOD. Alterations in MDA content, SOD activity and mRNA expression of immune inflammatory factors IL-6 and TNF- $\alpha$ were examined (Fig. 7). 

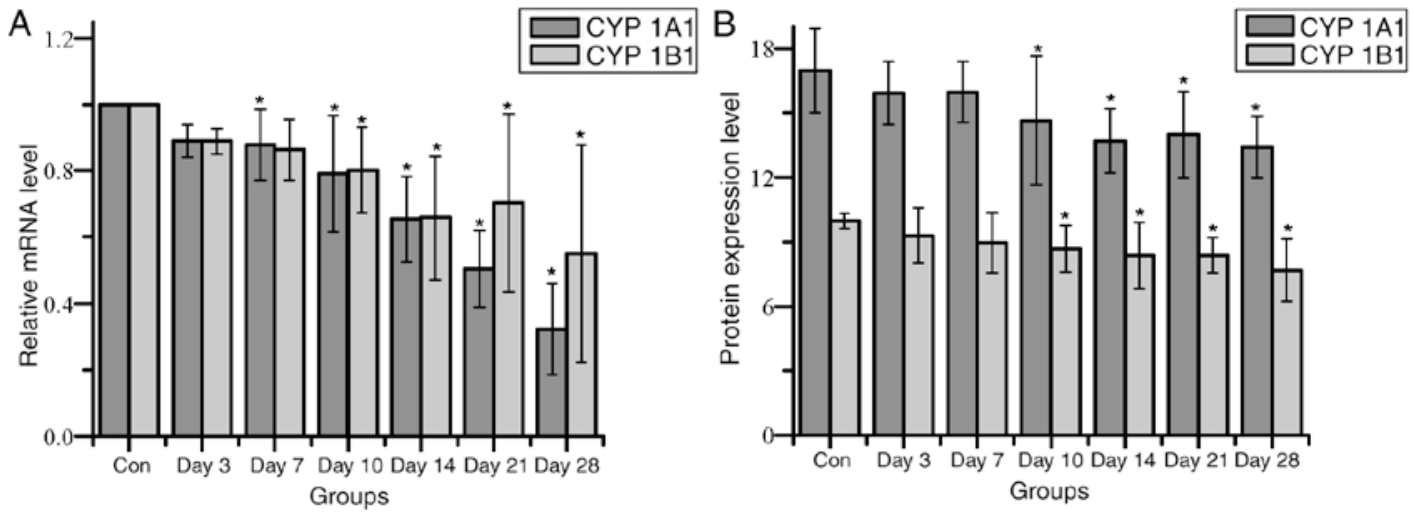

Figure 5. Relative expression levels of CYP1A1, CYP1B1 mRNA and protein. (A) CYP1A1 and CYP1B1 mRNA expression levels were detected by revers transcription-quantitative polymerase chain reaction. (B) The protein expression levels of CYP1A1 and CYP1B1 that were detected by ELISA. Each value is the mean \pm standard deviation of three experiments; ${ }^{*} \mathrm{P}<0.05$ vs. respective control. Con, control; CYP, cytochrome $\mathrm{P} 450$.
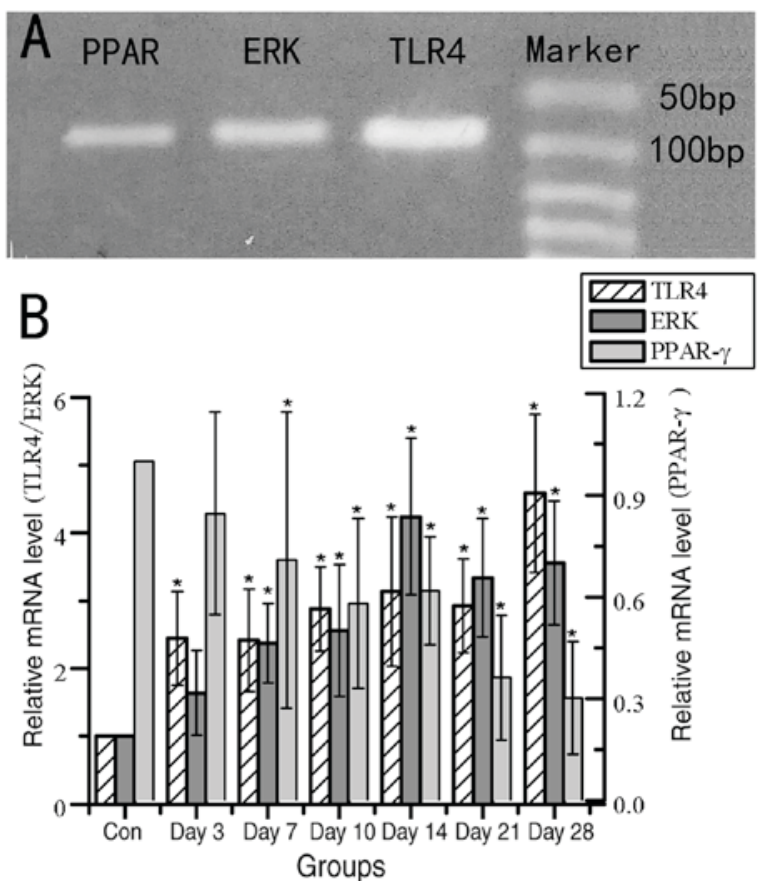

Figure 6. mRNA expression levels of TLR4, ERK and PPAR- $\gamma$ in isoniazid-induced rat liver injury. (A) Gel electrophoresis of the RT-qPCR amplified products and (B) the relative mRNA expression levels of TLR4, ERK and PPAR- $\gamma$; the RT-qPCR product lengths of TLR4, ERK and PPAR are 80, 101 and $106 \mathrm{bp}$, respectively. Data are presented as the mean \pm standard deviation of three experiments; ${ }^{P} \mathrm{P}<0.05$ vs. respective control. ERK, extracellular signal-regulated kinase; RT-qPCR, reverse transcription-quantitative polymerase chain reaction; PPAR- $\gamma$, peroxisome proliferator-activated receptor; TLR, toll-like receptor.

MDA content increased significantly at 14 days post-isoniazid treatment compared with the control group, and SOD activity significantly decreased from 3 days post-treatment (Fig. 7A). Correlation analysis of MDA and SOD with ALT and AST levels and CYP1A1 and CYP1B1 mRNA expression indicated that MDA was positively correlated with the degree of liver injury ( $\mathrm{r}=0.582$ and 0.499 , respectively; $\mathrm{P}<0.05)$, and negatively correlated with the expression of CYP1A1 and CYP1B1 ( $r=-0.603$ and -0.459 , respectively; $\mathrm{P}<0.05)$. SOD was negatively correlated with liver injury $(\mathrm{r}=-0.582$ and -0.453 , respectively; $\mathrm{P}<0.05)$, and positively correlated with the expression of CYP1A1 and CYP1B1 ( $r=0.524$ and 0.347 , respectively; $\mathrm{P}<0.05)$. Through partial correlation analysis of MDA and SOD with AST and ALT, it was demonstrated that excluding the effects of CYP1A1 and 1B1 expression alterations, the correlation coefficients between MDA and SOD with ALT and AST were decreased, indicating that the relationship became weak.

The mRNA expression of IL- 6 and TNF- $\alpha$ exhibited significant increases from day 3 post-treatment, compared with their respective controls (Fig. 7B). Correlation analysis indicated that IL- 6 were positively correlated with liver injury ( $\mathrm{r}=0.589$ and 0.492 , respectively; $\mathrm{P}<0.05$ ); the mRNA expression of IL-6 was negatively correlated with CYP1A1 and CYP1B1 expressions ( $\mathrm{r}=-0.750$ and -0.502 , respectively; $\mathrm{P}<0.05)$. TNF- $\alpha$ was also positively correlated with liver injury $(\mathrm{r}=0.356, \mathrm{P}<0.05 ; \mathrm{r}=0.234, \mathrm{P}>0.05)$; the mRNA expression of TNF- $\alpha$ was negatively correlated with CYP1A1 and CYP1B1 expressions $(\mathrm{r}=-0.432, \mathrm{P}<0.05 ; \mathrm{r}=-0.243, \mathrm{P}>0.05)$. Partial correlation analysis was performed to control the expression of CYP1A1 and CYP1B1; the correlations between IL-6, TNF- $\alpha$ and ALT, AST were decreased, and the correlation was not significant. These results indicated that the changes in the expressions of MDA, SOD, IL-6 and TNF- $\alpha$ in liver injury may be related to the expression levels of CYP1A1 and CYP1B1.

\section{Discussion}

The present study selected epigenetic mechanisms of drug-induced liver injury as the entry point to study the role of CpG island methylation in the CYP1A1 and CYP1B1 promoter regions in the process and mechanism of isoniazid-induced rat liver injury. Experiments were conducted to confirm that the highly methylated $\mathrm{CpG}$ islands in the CYP1A1 and CYP1B1 promoter regions may induce low expression of genes, so as to regulate rat liver injury induced by isoniazid, which may occur through the upregulation of TLR4 and ERK expression, the downregulation of PPAR $-\gamma$ expression and by promoting oxidative stress and inflammatory reaction.

Global DNA methylation is a well-known epigenetic feature of disease. Medicine may cause changes in the levels of genome methylation, which may lead to alterations in gene 

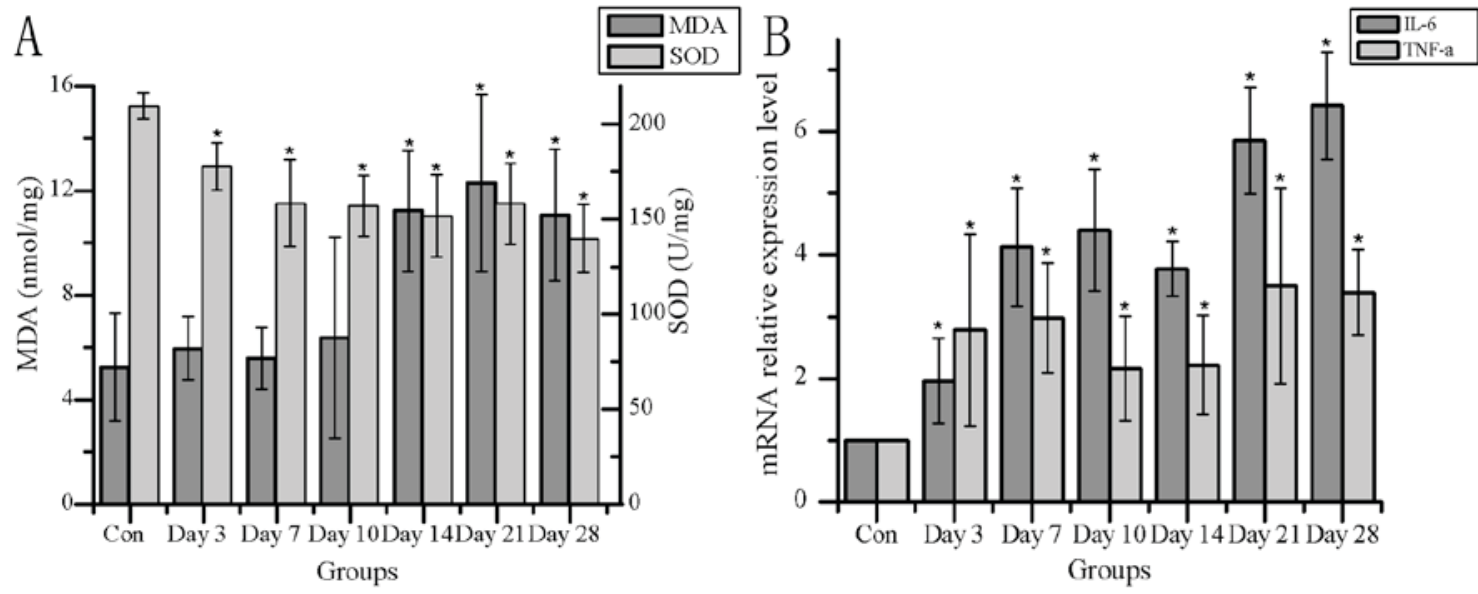

Figure 7. Expression levels of oxidative stress and inflammatory factors. (A) Activity of MDA and SOD. (B) mRNA expression levels of IL-6 and TNF- $\alpha$. Data are presented as the mean \pm standard deviation of three experiments; " $\mathrm{P}<0.05$ vs. respective control. MDA, malondialdehyde; SOD, superoxide dismutase; IL-6, inlterleukin-6; TNF- $\alpha$, tumor necrosis factor $\alpha$.

activity and phenotype. DNA hypomethylation is an important marker of disease, which can activate the repetitive sequence of the genome, affect the stability of the genome and increase the risk of cancer, atherosclerosis, Alzheimer's disease, psychiatric disorders and other diseases (23). Gene promoter region-specific hypermethylation and whole-genome hypomethylation are frequently found in tumor cells $(24,25)$. In the present study, the methylation level of the whole genome was detected by HPLC. The results revealed that the methylation level of whole genome was significantly reduced by day 7 post-isoniazid treatment, and reached its lowest levels at day 28 , which was $\sim 26 \%$ the methylation rate of the control group. The overall methylation level of DNA was downregulated, which was consistent with previous studies (16).

Changes in DNA methylation may affect transcription initiation and lead to the occurrence of disease and cancer. $\mathrm{CpG}$ island methylation is more common than whole-genome methylation, and $\mathrm{CpG}$ island methylation levels are altered as early as the whole-genome methylation level, is an early event of disease (24). It has been previously reported that high methylation of the CYP1A1 gene may cause transcriptional inactivation, which leads to the decrease of metabolic activation. DNA methylation may be used to make early prediction and prognosis evaluations for the occurrence and development of liver cancer $(26,27)$. Overexpression of CYP1B1 in the liver may be one of the increased risks of liver cancer in patients with liver disease (28). In the present study, MSP was used to detect the methylation level of CYP1A1 and CYP1B1 promoters in the liver tissue rats treated with intragastric administration of isoniazid. The results revealed that the CYP1A1 and CYP1B1 promoter regions were highly methylated; methylation levels at each time point were higher than that in the control group, and there was a significant difference from day 3. Alterations in methylation in the experimental rats were noted to occur in the early stage. RT-qPCR and ELISA demonstrated that both mRNA and protein expression of the two genes were decreased. Along with the upregulation of $\mathrm{CpG}$ island methylation in the promoter region of the gene, the gene expression level was downregulated, which was consistent with previous studies (29-31). DNA methylation leads to transcriptional inactivation or reduction and may by directly interfere with transcription factor binding or may indirectly attract methylated DNA binding factor, followed by the recruitment of histone deacetylase to generate invalid heterochromatin structure $(32,33)$.

The present study revealed that CYP1A1 and CYP1B1 promoter region $\mathrm{CpG}$ islands were highly methylated and their expression levels were reduced, but the changes of CYP1A1 were more obvious compared with those in CYP1B1. A previous study reported that estrogen receptor $\alpha(\mathrm{ER} \alpha)$ represses CYP1A1 expression by targeting DNA (cytosine-5)-methyltransferase 3B (Dnmt3B) and the associated DNA methylation of the promoter, but it had no effect on CYP1B1 (34). Variations in the expression levels of Dnmt3B isoforms may partly explain the effects of ER $\alpha$ on CYP1A1 regulation (34). Therefore, the differences in CYP1A1 and CYP1B1 methylation levels in the present study may be due to regulation by different types of methyltransferases. The expression of CYP1A1 was higher compared with CYP1B1 in a previous study of liver basal expression (35). Abnormal methylation of CYP1B1 and changes in expression levels are frequently observed in tumors and other malignant diseases (36). These data indicated that CYP1A1 methylation and gene expression are more evident compared with the changes of CYP1B1 in isoniazid-induced liver injury, which supports the conclusions made by the present study.

The TLR4 signaling pathway and PPAR- $\gamma$ have been reported to be involved in the occurrence of liver injury in different degrees $(17,21)$. A number of studies on the prevention and treatment of liver injury and liver fibrosis have also demonstrated that drugs may reduce the production of inflammatory factors and alleviate lipid peroxidation by downregulating TLR4 and ERK expression and upregulating PPAR- $\gamma$ expression, thereby effectively reducing liver disease (37-39). In the present study, the expression of TLR4 and ERK were upregulated and the expression of PPAR- $\gamma$ was downregulated compared with the control group, which was consistent with the results of previous studies on liver injury. These changes were significantly correlated with the mRNA expression level of CYP1A1 and CYP1B1 $(\mathrm{P}<0.05)$. Partial correlation analysis 
indicated that the expression level of TLR4, ERK and PPAR- $\gamma$ were affected by the expression levels of CYP1A1 and CYP1B1 in liver injury. Therefore, altered expression of CYP1A1 and CYP1B1 through the changes of TLR4, ERK and PPAR- $\gamma$ may regulate the occurrence of hepatic injury induced by isoniazid. However, the processes of isoniazid-induced liver injury are complex, and involve changes to multiple signaling pathways and related factors, whereas the present study only discusses the change of TLR4 signal pathway and the expression of PPAR- $\gamma$.

Oxidative stress and inflammation are closely related to liver injury; activation of the TLR4 signaling pathway may lead to the production of inflammatory factors and activation of immune cells, which may contribute to the occurrence of liver injury (17). The powerful anti-inflammatory and anti-oxidative effects of PPAR- $\gamma$ also serve an irreplaceable role in the liver. The present study demonstrated that MDA content increased, SOD activity decreased and the expression levels of IL- 6 and TNF- $\alpha$ mRNA increased. The changes of these factors were significantly correlated with the expression of CYP1A1 and CYP1B1, which suggested that the expression of CYP1A1 and CYP1B1, by upregulating the expression of TLR4 signaling pathway and downregulating PPAR- $\gamma$, aggravated the oxidative damage and immune damage, and further regulated the occurrence of liver injury.

In conclusion, $\mathrm{CpG}$ island hypermethylation of CYP1A1 and CYP1B1 promoter regions regulated the occurrence of rat liver injury induced by isoniazid, and the mechanism may be through effecting the expression of TLR4 signaling pathway and PPAR- $\gamma$, thus contributing to oxidative stress and inflammation, leading to liver damage. However, additional experiments are required to verify the present results and, as only one aspect of the possible mechanisms in isoniazid-induced liver injury was discussed, future studies may identify potential methyltransferase inhibitors and other mechanisms related to liver injury.

\section{Acknowledgements}

Thanks to the strong support of The National Natural Science Foundation of China (grant no. 81041096) and The Innovation and Entrepreneurship Training Program for College Students in Hebei Province (grant no. X2015051).

\section{References}

1. Huang YS: Recent progress in genetic variation and risk of antituberculosis drug-induced liver injury. J Chin Med Assoc 77: $169-173,2014$

2. Zhang S, Pan H, Peng X, Lu H, Fan H, Zheng X, Xu G, Wang M and Wang J: Preventive use of a hepatoprotectant against anti-tuberculosis drug-induced liver injury: A randomized controlled trial. J Gastroenterol Hepatol 31: 409-416, 2016.

3. Corsini A and Bortolini M: Drug-induced liver injury: The role of drug metabolism and transport. J Clin Pharmacol 53: 463-474, 2013.

4. Hrycay EG and Bandiera SM: Involvement of cytochrome $\mathrm{P} 450$ in reactive oxygen species formation and cancer. Adv Pharmacol 74: 35-84, 2015.

5. Shahabi P, Siest G, Meyer UA and Visvikis-Siest S: Human cytochrome P450 epoxygenases: Variability in expression and role in inflammation-related disorders. Pharmacol Ther 144: 134-161, 2014.

6. Feng FM, Guo M, Chen Y, Li SM, Zhang P, Sun SF and Zhang GS: Genetic polymorphisms in metabolic enzymes and susceptibility to anti-tuberculosis drug-induced hepatic injury. Genet Mol Res 13: 9463-9471, 2014.
7. Turesky RJ and Le Marchand L: Metabolism and biomarkers of heterocyclic aromatic amines in molecular epidemiology studies: Lessons learned from aromatic amines. Chem Res Toxicol 24: 1169-1214, 2011.

8. Rodenhiser D and Mann M: Epigenetics and human disease: Translating basic biology into clinical applications. CMAJ 174: 341-348, 2006.

9. Picascia A, Grimaldi V, Pignalosa O, De Pascale MR, Schiano C and Napoli C: Epigenetic control of autoimmune diseases: From bench to bedside. Clin Immunol 157: 1-15, 2015.

10. Benakanakere M, Abdolhosseini M, Hosur K, Finoti LS and Kinane DF: TLR2 promoter hypermethylation creates innate immune dysbiosis. J Dent Res 94: 183-191, 2015.

11. Zeybel M, Hardy T, Robinson SM, Fox C, Anstee QM, Ness T, Masson S, Mathers JC, French J, White S and Mann J: Differential DNA methylation of genes involved in fibrosis progression in non-alcoholic fatty liver disease and alcoholic liver disease. Clin Epigenetics 7: 25, 2015.

12. Dong Y, Zhao H, Li H, Li X and Yang S: DNA methylation as an early diagnostic marker of cancer (Review). Biomed Rep 2: 326-330, 2014.

13. Crary-Dooley FK, Tam ME, Dunaway KW, Hertz-Picciotto I, Schmidt RJ and LaSalle JM: A comparison of existing global DNA methylation assays to low-coverage whole-genome bisulfite sequencing for epidemiological studies. Epigenetics 12: 206-214, 2017.

14. He L, Gao L, Shi Z, Li Y, Zhu L, Li S, Zhang P, Zheng G, Ren Q, Li Y, et al: Involvement of cytochrome P450 1A1 and glutathione S-transferase $\mathrm{P} 1$ polymorphisms and promoter hypermethylation in the progression of anti-tuberculosis drug-induced liver injury: A case-control study. PLoS One 10: e0119481, 2015.

15. Shen L, Zhang B, Sun S and Feng F: Methylation of cytochrome p450 2E1 promoter induced by low dosage of isoniazid. Environ Toxicol Pharmacol 36: 149-151, 2013.

16. Zhang B, Sun S, Shen L, Zu X, Chen Y, Hao J, Huang X and Feng F: DNA methylation in the rat livers induced by low dosage isoniazid treatment. Environ Toxicol Pharmacol 32: 486-490, 2011.

17. Akai S, Uematsu Y, Tsuneyama K, Oda S and Yokoi T: Kupffer cell-mediated exacerbation of methimazole-induced acute liver injury in rats. J Appl Toxicol 36: 702-715, 2016.

18. Takai S, Higuchi S, Yano A, Tsuneyama K, Fukami T, Nakajima M and Yokoi T: Involvement of immune- and inflammatory-related factors in flucloxacillin-induced liver injury in mice. J Appl Toxicol 35: 142-151, 2015.

19. Park SW, Kang JW and Lee SM: Role of Kupffer cells in ischemic injury in alcoholic fatty liver. J Surg Res 194: 91-100, 2015.

20. Bahari A, Mehrzad J, Mahmoudi M, Bassami MR and Dehghani H: Cytochrome P450 isoforms are differently up-regulated in aflatoxin $\mathrm{B}_{1}$-exposed human lymphocytes and monocytes. Immunopharmacol Immunotoxicol 36: 1-10, 2014.

21. Mahmoud AM and Al Dera HS: $18 \beta$-Glycyrrhetinic acid exerts protective effects against cyclophosphamide-induced hepatotoxicity: Potential role of PPAR $\gamma$ and Nrf2 upregulation. Genes Nutr 10: 41, 2015.

22. Livak KJ and Schmittgen TD: Analysis of relative gene expression data using real-time quantitative PCR and the 2(-Delta Delta C(T)) method. Methods 25: 402-408, 2001.

23. Pogribny IP and Beland FA: DNA hypomethylation in the origin and pathogenesis of human diseases. Cell Mol Life Sci 66: 2249-2261, 2009.

24. Ozden S, Turgut Kara N, Sezerman OU, Durasi İM, Chen T, Demirel G, Alpertunga B, Chipman JK and Mally A: Assessment of global and gene-specific DNA methylation in rat liver and kidney in response to non-genotoxic carcinogen exposure. Toxicol Appl Pharmacol 289: 203-212, 2015.

25. Meng H, Cao Y, Qin J, Song X, Zhang Q, Shi Y and Cao L: DNA methylation, its mediators and genome integrity. Int J Biol Sci 11: 604-617, 2015.

26. Mah WC and Lee CG: DNA methylation: Potential biomarker in hepatocellular carcinoma. Biomark Res 2: 5, 2014.

27. Villanueva A, Portela A, Sayols S, Battiston C, Hoshida Y, Méndez-González J, Imbeaud S, Letouzé E, Hernandez-Gea V, Cornella $\mathrm{H}$, et al: DNA methylation-based prognosis and epidrivers in hepatocellular carcinoma. Hepatology 61: 1945-1956, 2015.

28. Kurzawski M, Dziedziejko V, Post M, Wójcicki M, Urasińska E, Miętkiewski J and Droździk M: Expression of genes involved in xenobiotic metabolism and transport in end-stage liver disease: Up-regulation of ABCC4 and CYP1B1. Pharmacol Rep 64: 927-939, 2012. 
29. Bernstein BE, Meissner A and Lander ES: The mammalian epigenome. Cell 128: 669-681, 2007.

30. Tang W, Wang $\mathrm{C}, \mathrm{Fu} \mathrm{F}$ and Chen Q: RhoBTB2 gene in breast cancer is silenced by promoter methylation. Int J Mol Med 33: 722-728, 2014

31. Ball MP, Li JB, Gao Y, Lee JH, LeProust EM, Park IH, Xie B, Daley GQ and Church GM: Targeted and genome-scale strategies reveal gene-body methylation signatures in human cells. Nat Biotechnol 27: 361-368, 2009.

32. Beedanagari SR, Taylor RT, Bui P, Wang F, Nickerson DW and Hankinson O: Role of epigenetic mechanisms in differential regulation of the dioxin-inducible human CYP1A1 and CYP1B1 genes. Mol Pharmacol 78: 608-616, 2010.

33. Ingelman-Sundberg $M, Z$ Zhong $X B$, Hankinson $O$, Beedanagari $S$, Yu AM, Peng L and Osawa Y: Potential role of epigenetic mechanisms in the regulation of drug metabolism and transport. Drug Metab Dispos 41: 1725-1731, 2013.

34. Marques M, Laflamme L and Gaudreau L: Estrogen receptor $\alpha$ can selectively repress dioxin receptor-mediated gene expression by targeting DNA methylation. Nucleic Acids Res 41: 8094-8106, 2013.

35. Gao K, Brandt I, Goldstone JV and Jönsson ME: Cytochrome $\mathrm{P} 450$ 1A, 1B, and 1C mRNA induction patterns in three-spined stickleback exposed to a transient and a persistent inducer. Comp Biochem Physiol C Toxicol Pharmacol 154: 42-55, 2011.
36. Tokizane T, Shiina H, Igawa M, Enokida H, Urakami S, Kawakami T, Ogishima T, Okino ST, Li LC, Tanaka Y, et al: Cytochrome P450 1B1 is overexpressed and regulated by hypomethylation in prostate cancer. Clin Cancer Res 11: 5793-5801, 2005.

37. Zhao Y, Ma X, Wang J, He X, Hu Y, Zhang P, Wang R, Li R, Gong M, Luo S and Xiao X: Curcumin protects against CCl4-induced liver fibrosis in rats by inhibiting HIF-1a through an ERK-dependent pathway. Molecules 19: 18767-18780, 2014.

38. Qian H, Shi J, Fan TT, Lv J, Chen SW, Song CY, Zheng ZW, Xie WF and Chen YX: Sophocarpine attenuates liver fibrosis by inhibiting the TLR4 signaling pathway in rats. World J Gastroenterol 20: 1822-1832, 2014.

39. Zhang F, Wang X, Qiu X, Wang J, Fang H, Wang Z, Sun Y and Xia Z: The protective effect of esculentoside A on experimental acute liver injury in mice. PLoS One 9: e113107, 2014.

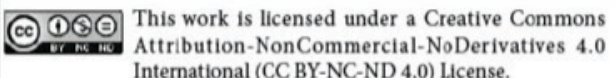
International (CC BY-NC-ND 4.0) License. 